\title{
Signaled escape and signaled punishment: Additional instrumental conditioning paradigms*
}

\author{
PAUL J. WOODS \\ Hollins College, Roanoke, Va. 24020
}

Two experiments were conducted in which signals were utilized to inform rats of the consequences of making an escape response from an aversive situation. In Experiment I, one signal predicted that a decrease in the level of aversive intensity would follow an instrumental escape response, while the other predicted no change in the level of aversive intensity. In Experiment II, one signal again predicted a decrease in aversive intensity, while the other predicted an increase. In both studies differential performance occurred under these signals, supporting the behavioral reality of signaled escape and signaled punishment in an escape context as instrumental conditioning paradigms.

In a classification scheme for instrumental conditioning, Grant (1964) delineated eight basic paradigms generated by all possible combinations of three dichotomous dimensions. One of the logical possibilities missing from his scheme, however, is a signaled escape paradigm. In this case, the organism is exposed to an aversive situation and distinctive cues are present which signal in advance whether or not the relevant instrumental response will result in successful escape or "relief." Thus, on one trial a cue tells the organism that his responding will result in successful escape from the aversive situation; on another trial a different cue, which, of course, can be the mere absence of the other cue, tells him that the same instrumental response will not succeed in producing "relief." It seems reasonable to expect that Ss can learn to respond differentially to such a situation, but this paradigm has apparently received no experimental study until recently. Davenport and his students (Davenport, 1970; Davenport \& Eschenbrenner, 1970; Davenport \& Lerner, 1968) have used this paradigm and, although acquisition of a discrimination was not the primary interest in these studies, they report varying degrees of success in obtaining discriminative control.

The present studies focus on the acquisition performance itself, and they were conducted using techniques and procedures that relate them to a series of investigations from our laboratory. (See, for example, Woods, 1967; Woods, 1973; Woods \& Holland, 1966; Woods, Markman, Lynch, \& Stokely, 1972.)

*This work was supported in part by Public Health Service Research Grant M-02883 from the National Institute of Mental Health and in part by National Science Foundation Undergraduate Research Participation Grant GY-10,000. Und ergraduate Research Participation Grant GY-10,000.
Requests for reprints should be sent to Paul J. Woods, Department of Psychology, Hollins College, Roanoke, Virginia 24020.

\section{EXPERIMENT I Method}

Subjects

Twenty-four male Long-Evans rats, obtained from Flow Laboratories, Dublin, Virginia, were used. They averaged approximately $275 \mathrm{~g}$ during training and were maintained ad lib on food and water.

\section{Apparatus}

The water-escape apparatus that has been described previously (Woods, 1964) was used with the addition of a second goal tank. With this apparatus, $S$ must learn to swim down a cold alley tank, whereupon he is placed in a warmer goal tank if the trial is to be reinforced. For a nonreinforced trial, $S$ escapes to the second goal tank, which is the same temperature as the alley. That is, for a reinforced trial the aversiveness of the cold water is reduced and for a nonreinforced trial it is not. The temperature in all tanks was controlled automatically and precisely $\left( \pm 0.1^{\circ} \mathrm{C}\right)$ through connections to reservoirs equipped with Bronwill constant-temperature circulators.

Between trials, a heated detention cage was used to house Ss.

A bank of two $40-\mathrm{W}$ fluorescent tubes, suspended $75 \mathrm{~cm}$ above the alley, served as the signal; for half of the Ss, light-on signaled that the escape response would be reinforced or terminated with "relief" and, for the other half, the reverse was the case.

\section{Procedure}

The alley temperature throughout the study was maintained at $15^{\circ} \mathrm{C}$. This temperature, which defines our drive stimulus intensity, is described by human Ss after a 5-sec exposure of the hand as cold, uncomfortable, and somewhat painful (Woods, Griffith, Page, \& Rodier, 1967). On a reinforced trial, Ss escaped to a tank maintained at $40^{\circ} \mathrm{C}$, a temperature rated by humans, in the same manner as above, as warm, nonpainful, and comfortable. On a nonreinforced trial, of course, the second goal tank was the same $20^{\circ} \mathrm{C}$ as the alley so that no relief was obtained following the escape response.

The Ss were run for 26 acquisition trials each day for 3 consecutive days. For all Ss on each day, the same sequence of signaled reinforced and nonreinforced trials was used. Trials 1, 2, $4,6,7,10,13,16,17,18,21,25$, and 26 were reinforced. This sequence was arrived at through a table of random numbers, with the following restrictions: The first two trials were to be reinforced, there were to be no more than three reinforced or nonreinforced trials in succession, and there were to be an equal number of each.

Ss were run in subgroups of four by each of three Es. ${ }^{1}$ Each $E$ ran one group with light-on as the signal for reinforcement and one group with light-off as the signal. Within each subgroup, Ss were run so that each received a trial before the first $S$ received his next trial, etc. This procedure resulted in an intertrial interval of approximately $3 \mathrm{~min}$. For a trial, the signal light was first set as required by the schedule, then $S$ was removed from the detention cage and gently lowered into the starting end of the tank. When he reached the far end, he was placed in the appropriate goal tank for $20-25 \mathrm{sec}$ and then returned to the warmed detention box.

E recorded the total response time, as well as the time between two underwater photobeams, in a 36-in. midsection of the alley. Also, the behavior of $S$ in the midsection was carefully noted, and a record was made as to whether that distance was covered in a straightforward unbroken swim or whether there 


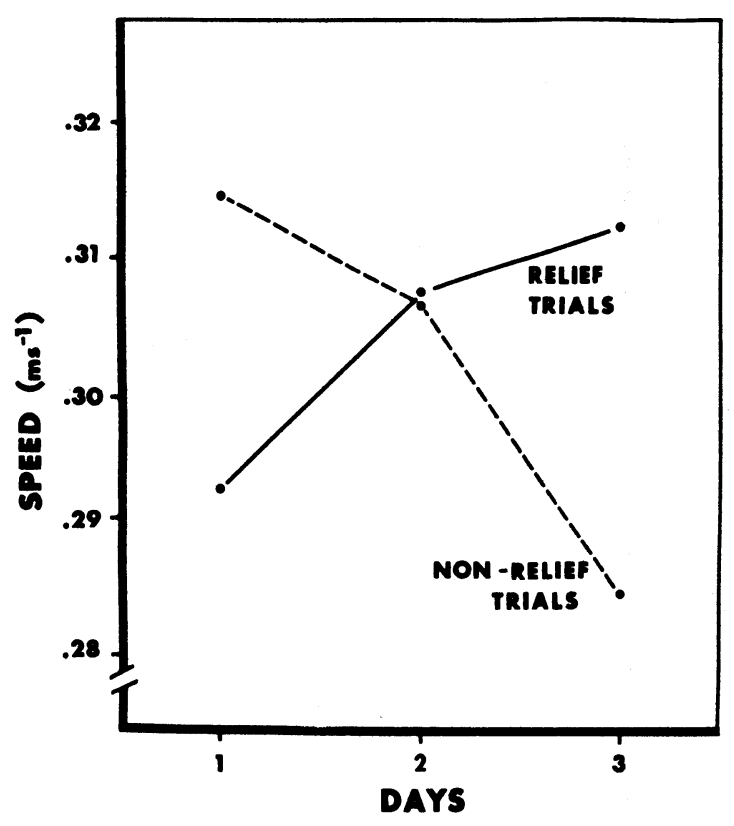

Fig. 1. Overall mean speeds for trials on which either "relief" or "nonrelief" was signaled.

was any interruption from competing behavior, such as clawing the walls or retracing. When there was an unbroken swim, we then had a measure of the vigor of the relevant escape response itself.

\section{Results}

Overall mean speeds for trials on which "relief" was signaled (R) are compared with trials on which "nonrelief" was signaled (NR) in Fig. 1. It is interesting to note that NR trials were significantly faster on Day 1 $[\mathrm{t}(23)=3.12, \mathrm{p}<.01]$, but by Day 3 the reverse was the case $[t(23)=3.36, p<.01]$. These average functions do reflect the most common pattern of performance change in individual Ss; $71 \%$ of the Ss swam faster on Day $3 \mathrm{R}$ trials as compared to Day 1 , and $71 \%$ swam slower on Day 3 NR trials as compared to Day 1.

For swimming speed itself, that is, speed between the two photobeams on trials when there were no major competing responses, we found a small but significant decline on NR trials from Day 1 to Day 3. On these trials they slowed from $0.349 \mathrm{msec}^{-1}$ on Day 1 to $0.324 \mathrm{msec}^{-1}$ on Day $3[\mathrm{t}(23)=2.25, \mathrm{p}<.05]$. This is in contrast to the fact that there was no significant change with this measure on $R$ trials.

The frequency with which such noncompeting response trials occurred also indicated discriminative behavior. Noncompeting response runs were made about $80 \%$ of the time on R trials and there was no trend or significant change over days. On NR trials, however, noncompeting response runs dropped from an average of $86.2 \%$ on Day 1 to $67.9 \%$ on Day $3[\mathrm{t}(23)=2.80$, $\mathrm{p}<.02]$. The frequency of such runs on Day 3 was also significantly less on $\mathrm{NR}$ trials than on $\mathrm{R}$ trials $[\mathrm{t}(23)=2.47, \mathrm{p}<.05]$.

\section{EXPERIMENT II}

Another logical paradigm for instrumental conditioning that was not included in Grant's (1964) classification is one in which a signal informs the organism that on a particular trial not only will he fail to escape or obtain "relief" but also he will actually find himself in a more aversive condition if he emits a particular response. This is a signaled punishment paradigm and, in the present study, it was combined with the signaled escape paradigm. Thus, on trials during which the "relief" signal is present, the swimming response by $\mathrm{S}$ is followed by placement in a warmer goal tank; on trials during which the punishment signal is present, the swimming response is followed by placement in a colder goal tank.

\section{Subjects}

\section{Method}

Twenty-four animals of the same strain and approximately the same weight as in Experiment I were obtained from the same supplier and maintained ad lib on food and water during the study.

\section{Apparatus}

There was no change from Experiment I.

\section{Procedure}

A $20^{\circ} \mathrm{C}$ alley temperature was used in this study. Human Ss, following a 5-sec exposure of the hand, describe this as cool, on the border between comfortable and uncomfortable, and nonpainful (Woods et al, 1967). On reinforced trials, Ss escaped to a warm, comfortable, and nonpainful $40^{\circ} \mathrm{C}$ in the first goal tank and, on punished trials, they were subjected to a very cold, uncomfortable, and painful $8^{\circ} \mathrm{C}$ in the second goal tank. The remaining procedure, including the trials which were reinforced, was the same as in Experiment $I$.

\section{Results}

Overall mean speeds for signaled "relief" trials (R) and for signaled "punishment" trials $(\mathrm{P})$ are shown in Fig. 2. The trends are quite comparable to those in Experiment I and, indeed, may even be accentuated. While the differences on Day 1 were not significant, $75 \%$ of the Ss were faster on P trials. Then by Day 3 the same reversal occurred as was seen in Experiment $I$. The $R$ trials were again significantly faster $[t(21)=2.65$, $p<.02]$; also, the difference between $R$ and $P$ trials was, on the average, almost twice as great as the difference between $\mathrm{R}$ and NR trials in the first study (compare Day 3 on Figs. 1 and 2). Again, the most common pattern for individual Ss was that shown in the mean curves; $59 \%$ had faster $\mathrm{R}$ trials in Day 3 compared to Day 1 and $86 \%$ had slower P trials.

As in Experiment $I$, the swimming speed per se on noncompeting response trials did not change significantly on $\mathrm{R}$ trials, but it did slow down on $\mathrm{P}$ trials between Days 1 and 2 from $0.329 \mathrm{msec}^{-1}$ to $0.292 \mathrm{msec}^{-1}[t(18)=3.91, \mathrm{p}<.002]$.

Finally, the frequency of noncompeting response trials again indicated discriminative behavior. Noncompeting response runs were made about $62 \%$ of the time on Day 1 for $R$ trials and there were no 
significant changes over days, but on $\mathrm{P}$ trials such noncompeting response runs dropped from $65.1 \%$ on Day 1 to $37.4 \%$ on Day $3[\mathrm{t}(21)=4.22, \mathrm{p}<.001]$. Similarly, the frequency of such runs on Day 3 was significantly less on $\mathbf{P}$ trials than on $\mathbf{R}$ trials $[\mathrm{t}(21)=2.12, \mathrm{p}<.05]$.

\section{Comparing Experiments I and II}

In looking at the general findings between these two experiments, there is an important difference at least worthy of note and certainly worthy of further investigation. If we look at just those trials on which "relief" was signaled in the two experiments, we find that the vigor of the ongoing response when other competing behaviors were not interfering (i.e., swimming speed itself) was almost comparable: The average swimming speed in Experiment II was $91 \%$ of the average swimming speed in Experiment I. Yet the overall total speed, which takes into account competing behaviors averaged on "relief" trials in Experiment II, was only $60 \%$ of the level obtained in Experiment I. Or, further, if we count the number of trials on which major competing responses occurred, we find that such interruptions in performance were about $3 \frac{1}{2}$ times more common on "relief" trials in Experiment II. While it is true that there were differences in alley temperature and alley-goal differential between the two studies, these differences were not of sufficient magnitude to account for such large performance differences on these signaled "relief" trials.

\section{DISCUSSION}

The present studies support the indications noted by Davenport and his students (Davenport, 1970; Davenport \& Eschenbrenner, 1970; Davenport \& Lerner, 1968) that the logical possibility of a signaled or discriminated escape paradigm does have reality. Our studies have clearly demonstrated that animals are capable of performing differentially to a signal which precedes "relief" in contrast to a signal which precedes "nonrelief." This conclusion is supported by several independent aspects of the data.

In Experiment II our use of punishment in an escape conditioning context is, we believe, also unusual. Typically, punishment consists of the initiation of an aversive event to an organism which, while it may be in a state of deprivation, is essentially in a nonaversive situation. That is, punishment is usually studied in an appetitive conditioning context. Here, however, we utilized an escape conditioning context: The organism was already in an aversive situation and punishment consisted of making the situation even more aversive. (In this context it could be argued that the usual procedure is merely the end point of a continuum of possibilities and, therefore, a special case of the punishment paradigm.) In any case, Experiment II demonstrated that signaling such operations could produce differential performance.

Finally, in the comparison made above between Experiments I and II, what we are tentatively suggesting is that escape performance, even on trials where "relief" is signaled, depends on the context in which that trial occurs. If the context is that of "relief" vs punishment, then performance is inferior compared to the context of "relief" vs "nonrelief." In a previous study (Woods et al, 1972), we documented how the effects of a "nonrelief" trial carried over for several subsequent "relief" trials, and the present discussion suggests that a punishing experience has an even greater impact.

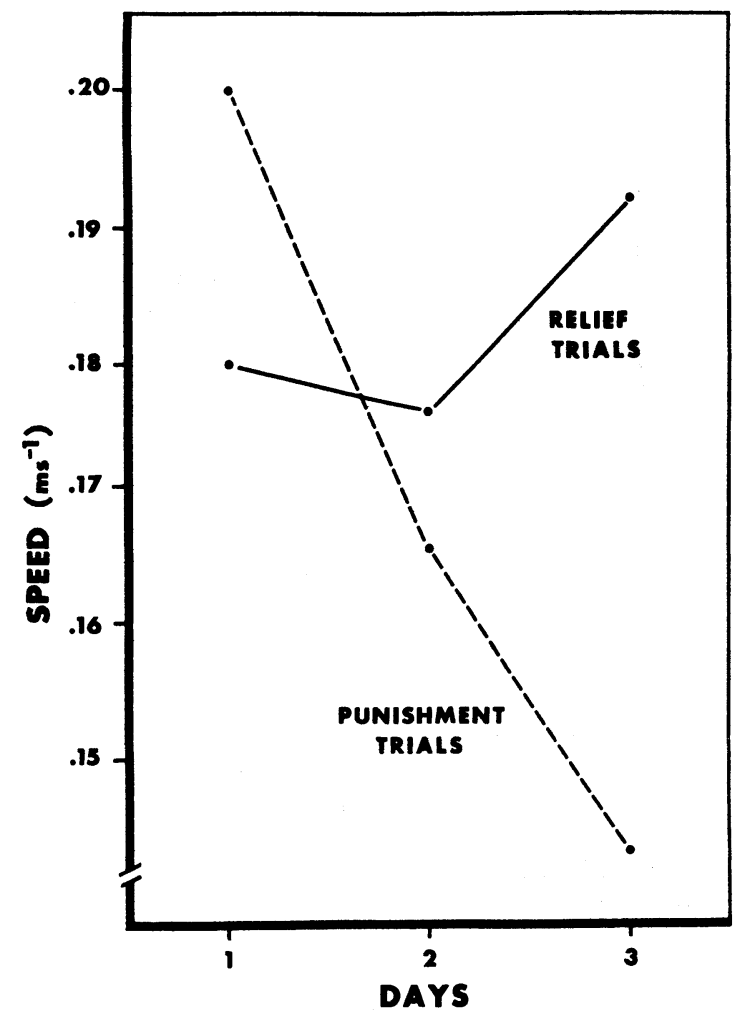

Fig. 2. Overall mean speeds for trials on which either "relief" or punishment was signaled.

\section{REFERENCES}

Davenport, D. G. The secondary positive reinforcing properties of the cue in "automated" discriminated escape conditioning. Psychonomic Science, 1970, 21, 149-150.

Davenport, D. G., \& Eschenbrenner, A. J. Double-intermittent rew ard scheduling and secondary-reinforcer strength: Discriminated escape. Psychonomic Science, 1970, 21, 151-152.

Davenport, D. G., \& Lerner, J. J. The cue in discriminated escape conditioning as a secondary positive reinforcer. Psychonomic Science, 1968, 13, 47-48.

Grant, D. A. Classical and operant conditioning. In A. W. Melton (Ed.), Categories of human learning. New York: Academic Press, 1964. Pp. 1-31

Woods, P. J. Water tank apparatus for instrumental escape conditioning. Psychological Reports, 1964, 14, 167-170.

Woods, P. J. Performance changes in escape conditioning following shifts in the magnitude of reinforcement. Journal of Experimental Psychology, 1967, 20, 787-793.

woods, P. J. The effects of a sudden reduction in anticipated "relief." Bulletin of the Psychonomic Society, 1973, 1, 5-8.

Woods, P. J., Griffith, B. A., Page, R. P., \& Rodier, P. M. Human responses to various conditions of water temperature. Perception \& Psychophysics, 1967, 2, 157-160.

Woods, P. J \& Holland, C. H. Instrumental escape conditioning in a water tank: Effects of constant reinforcement at different points on the continuum of drive stimulus intensity. Journal of Comparative \& Physiological Psychology, 1966, 62 403-408.

Woods, P. J., Markman, B. S., Lynch, W. C., \& Stokely, S. N. $P$ artial reinforcement effects in instrumental escape conditioning. Learning \& Motivation, 1972, 3, 279-292.

NOTE

1. The author wishes to thank Virginia T. Scott, Frances Whitaker Schoonover, and Lynne White for their help with these studies.

(Received for publication February 8, 1973.) 